\title{
How the magnitude of clinical severity and recurrence risk affects reproductive decisions in adult males with different forms of progressive muscular dystrophy
}

\author{
Sabine Eggers, Mayana Zatz
}

\begin{abstract}
The reproductive history of 177 male patients affected with Becker (BMD) ( $n=69)$, limb-girdle (LGMD) $(n=54)$, and facioscapulohumeral (FSHMD) $(n=54)$ muscular dystrophy (MD) was analysed according to severity of the disease (BMD>LGMD>FSHMD) and magnitude of recurrence risk (RR) (high for FSHMD, intermediate for BMD, and low for LGMD). Additionally, 62 male patients were interviewed on psychosocial issues, in order to disentangle the factors influencing reproductive decisions among patients affected with $M D$.

Among male adults, significantly more FSHMD than LGMD or BMD patients were married and had children. Age specific reproductive outcome was 0.310.32 for BMD, 0.51-0.62 for LGMD, and 0.58-1.02 for FSHMD, reflecting the influence of the disease's severity. High RRs did not significantly diminish reproduction after genetic counselling or correlate with less prospective desire for children. Instead, early onset, severity of the disease, and past reproductive history were found to diminish reproductive outcome after genetic counselling, and prospective family planning was also found to be influenced by past reproductive history as well as by emotional/sexual dysfunction with the opposite sex.

$(\Im$ Med Genet 1998;35:189-195)
\end{abstract}

Keywords: genetic counselling; psychosocial; muscular dystrophies

Muscular dystrophy must have worried humanity at least since the Egyptian civilisation, since there are paintings and reliefs older than 4500 years showing people with lumbar lordosis and calf hypertrophy. ${ }^{1}$ More than 30 different types of progressive muscular dystrophy (PMD) are known today, all still untreatable, but the present study focused on the most common adult forms, that is, Becker (BMD), limb-girdle (LGMD), and facioscapulohumeral (FSHMD) muscular dystrophy.

$B M D$, an $X$ linked condition with an incidence of approximately 1 in 30000 males, is milder than its allelic form, Duchenne muscular dystrophy (DMD). The course of the disease is very variable, with onset usually in the second decade and confinement to a wheelchair always after the age of 16 . Life expectancy is slightly reduced. BMD is caused by mutations in a huge gene located at Xp21, which leads to quantitative and qualitative defects in the protein dystrophin. ${ }^{34}$

LGMD, usually an autosomal recessive (AR) trait affecting both genders equally, is characterised by weakening of pelvic and scapular girdle musculature with considerable phenotypic variability as well as genetic heterogeneity. There are at least six different AR forms which are LGMD2A at $15 \mathrm{q},{ }^{5}$ LGMD2C at $13 \mathrm{q},{ }^{6}$ LGMD2B at $2 \mathrm{p},{ }^{7}$ LGMD2D at $17 \mathrm{q},{ }^{8}$ LGMD2E at $4 \mathrm{q},{ }^{9}{ }^{10}$ and LGMD2F at 5q. ${ }^{11}$ In some patients the course is as severe as DMD, while in others ambulation is preserved throughout adulthood conferring a clinical course very similar to the milder forms of BMD. Life expectancy is variable.

Finally, FSHMD is an autosomal dominant condition caused by mutations at $4 \mathrm{q} 35 .{ }^{12}$ The onset is usually in early adulthood leading to a slowly progressive and variable muscular weakness, affecting the face, the upper limb girdle, and sometimes the lower limbs as well. Severity is extremely variable, so that approximately $30 \%$ do not even notice any clinical symptoms, whereas $10 \%$ become wheelchair dependent in late phases of the disease. ${ }^{13}$ The incidence is similar to LGMD and life expectancy is not reduced.

New advances related to the molecular identification of disease causing genes are allowing differential, prenatal (PND), and preclinical diagnosis (PCD) in a rapidly growing number of hereditary diseases. While many genetic tests transform probabilities into certainties, they often lead to psychosocial and ethical dilemmas at genetic counselling sessions (GC), particularly in questions related to reproduction.

Numerous reports on the impact and the efficiency of GC have been written. In some studies, counsellees report that GC and especially the magnitude of $R R$ were important for their family planning. ${ }^{14-16}$ Accordingly, our previous study on this issue showed that the reproductive outcome of women at risk for DMD varied according to the magnitude of the $R R$ as well as how closely related they were to the affected person in the family. ${ }^{17}$ However, other studies indicate that the past reproductive history may be more important than the actual RR. ${ }^{18-21}$ Interestingly, the "gestalt" of a hereditary disease can have a greater influence on the patients than RRs or any other isolated aspect, suggesting a faint direct and linear 
Table 1 Reproductive outcome and family planning among male adults with PMD

\begin{tabular}{|c|c|c|c|c|}
\hline & $B M D$ & $L G M D$ & FSHMD & $p$ \\
\hline No of patients & 69 & 54 & 54 & \\
\hline Children per patient & $0.51 \pm 1.02$ & $0.83 \pm 1.33$ & $2.04 \pm 2.30$ & \\
\hline Children per normal brother & $1.57 \pm 1.50$ & $1.33 \pm 1.59$ & $2.00 \pm 1.50$ & \\
\hline Children per Paulista ${ }^{\star}$ & 1.64 & 1.64 & 3.52 & \\
\hline Reproductive outcome $†$ & 0.31 to 0.32 & 0.51 to 0.62 & 0.58 to 1.02 & \\
\hline Singles & $49(71 \%)$ & $34(63 \%)$ & $12(22 \%)$ & $<0.05$ \\
\hline Age at assessment & $30.94 \pm 8.86$ & $26.45 \pm 7.59$ & $28.33 \pm 10.31$ & \\
\hline Age at GC & $19.94 \pm 7.54$ & $23.41 \pm 7.95$ & $22.27 \pm 7.93$ & \\
\hline Vignos grade & $4.90 \pm 2.57$ & $4.10 \pm 2.08$ & $2.33 \pm 1.61$ & \\
\hline Interviewed single patients & 16 & 16 & 4 & \\
\hline Who do not want to marry & $7 / 16$ & $4 / 16$ & 0 & \\
\hline Who want (more) children & $7 / 16$ & $12 / 16$ & $2 / 4$ & \\
\hline Who want marriage but no children & $2 / 16$ & 0 & $2 / 4$ & \\
\hline Retention of GC information & $1.06 \pm 0.68$ & $1.19 \pm 0.83$ & $1.50 \pm 0.58$ & \\
\hline With emotional/sexual dysfunction & $13 / 16$ & $11 / 16$ & $5 / 6$ & \\
\hline Married & $20(29 \%)$ & $20(37 \%)$ & $42(78 \%)$ & $<0.05$ \\
\hline Age at assessment & $36.00 \pm 9.18$ & $37.24 \pm 9.34$ & $47.81 \pm 16.35$ & \\
\hline Age at GC & $30.20 \pm 7.22$ & $34.67 \pm 11.67$ & $34.00 \pm 9.79$ & \\
\hline Vignos grade at assessment & $4.06 \pm .1 .98$ & $4.47 \pm 1.87$ & $3.11 \pm 1.62$ & \\
\hline With children at assessment & $17(25 \%)$ & $16(29 \%)$ & $39(72 \%)$ & $<0.01$ \\
\hline \multicolumn{5}{|l|}{ Number of children born } \\
\hline Up to assessment & 35 & 45 & 110 & \\
\hline Before onset & $6 / 29=21 \%$ & $10 / 38=26 \%$ & $47 / 88=53 \%$ & $<0.05$ \\
\hline Before GC & $13 / 29=45 \%$ & $27 / 38=71 \%$ & $28 / 88=32 \%$ & NS \\
\hline After GC & $10 / 29=34 \%$ & $1 / 38=3 \%$ & $13 / 88=15 \%$ & $<0.05$ \\
\hline Unknown & 6 & 7 & 22 & \\
\hline Interviewed married patients & 6 & 6 & 14 & \\
\hline Children/patient & $8 / 6=1.33$ & $16 / 6=2.67$ & $21 / 14=1.50$ & \\
\hline Children born after GC/patient & 1.00 & 0.16 & 0.37 & \\
\hline Children/patient/married year & 0.17 & 0.15 & 0.15 & \\
\hline Who want (more) children & $1 / 6$ & 0 & $2 / 14$ & \\
\hline Retention of GC information & $1.67 \pm 0.52$ & $1.17 \pm 0.75$ & $1.29 \pm 0.61$ & \\
\hline With emotional/sexual dysfunction & $3 / 6$ & $4 / 6$ & $8 / 18$ & \\
\hline
\end{tabular}

$\star$ Paulista: general male population from São Paulo of comparable age (source: IBGE, 1980).

†Based on the mean number of children per male of general population (first value) and on healthy patient's brother (second value).

influence of RR and a low participation of cognitive processes in reproductive decisions. ${ }^{22-25}$

Therefore, the purpose of the present study was to answer the following question: which are the factors influencing reproductive outcome and prospective family planning after GC among male adult patients affected with different progressive muscular dystrophies: magnitude of recurrence risk ( $R R)$, severity of the disease, reproductive history, and/or psychosocial factors?

\section{Patients and methods}

All patients studied were diagnosed and counselled at the Centro de Miopatias at the University of São Paulo. Since the laboratory is connected to the Brazilian Association of Muscular Dystrophy (ABDIM), families are followed up by geneticists, physicians, physiotherapists, a psychologist, and an art therapist. This fact, as well as the interest of the families in keeping updated about potential future treatments, allows continuous follow up and collection of new data.

Since BMD affects only males, females were excluded from the study in an attempt to circumvent differences between genders. Each group was case and control at the same time and included $69 \mathrm{BMD}, 54 \mathrm{LGMD}$, and 54 FSHMD adult ( $>18$ years) male patients. The influences of magnitude of $R R$, reproductive history, and grade of physical impairment on the number of children per patient were analysed according to 177 updated individual registers on natural history, as well as from appointments made during GC sessions.

From the total sample, 62 patients (22 BMD, 22 LGMD, and 18 FSHMD) were additionally interviewed to assess psychosocial functioning, socioeconomic status, comprehension and retention of $R R$, and prospective family planning. Diagnosis was based on clinical and neurological evaluation, family history, course of the disease, serum creatine kinase activities, muscle biopsy, and DNA analysis.

Genetic counselling (GC) consisted of a long conversation about diagnosis, prognosis, recurrence risk, and family planning issues, according to the patient's level of knowledge, interest, and emotional status. All patients were given a written report on the main aspects discussed during GC.

Reproductive outcome was assessed as the ratio of the mean number of children per patient of a specific group in relation to the mean number of children (1) per patient's normal brother and (2) per male belonging to the general population of São Paulo, according to official government data, ${ }^{26}$ both of comparable age.

Reproductive history refers to the number of children born to patients before and after onset of clinical signs as well as after GC.

Physical impairment of patients with BMD was classified according to Archibald and Vignos, ${ }^{27}$ ranging from 0 to 10 , where $V=0$ refers to preclinical patients and $V=10$ to patients totally dependent and confined to bed. For patients affected with the other two types of PMD we used the "Vignos scale" adapted by Brooke et $a l^{28} \mathrm{BMD}$ patients with loss of ambulation before the age of $20^{29}$ and LGMD and FSH patients with Vignos score $>3$ within 5 years of disease onset were classified as severe.

The psychosocial adjustment (according to the semistructured questionnaire WHO - Disability Assessment Schedule $^{30}$ ) as well as the socioeconomic status of each patient assessed 
during individual interviews are reported in detail elsewhere. ${ }^{31}$

Recurrence risks (RR) for the patients' children to inherit the deleterious gene were classified as: (1) low for LGMD (intermediate clinical severity), since the $R R$ is negligible as long as there is no consanguineous marriage; (2) intermediate for BMD (the severest of these three adult forms) since all patients' sons will be normal, but all daughters will be asymptomatic carriers, with a $50 \%$ RR of transmitting $\mathrm{BMD}$ to their sons; and (3) high for FSHMD (the mildest clinical form) with a $50 \%$ probability for patients' children of both sexes to inherit the deleterious gene.

For the comprehension and retention of the information received during GC we attributed the following arbitrary scores during individual interviews: $0=$ very poor (if the patient thought that his disease was transmitted by a virus, for example); $1=$ reasonable (if he knew about a $R R$, but imagined he "should not" have children); and $2=$ good (if he knew about the magnitude of the $R R$ and could explain the type of inheritance in his own words).

The prospective family planning was also assessed by individual interviews, where patients were asked to talk deliberately about their family size and wishes. If the patient reported discordance between himself and his wife, we considered only the patient's opinion.

\section{Results}

Significantly more FSHMD than BMD or LGMD patients were married and had significantly more children (table 1). Accordingly, age specific reproductive outcome was higher in FSHMD $(0.58-1.02)$ as compared to LGMD (0.51-0.62) and BMD (0.31-0.32). As expected, very few (4) out of the 28 severe BMD patients were married as opposed to 16 out of 41 typical cases $(p<0.01$, data not shown) and only 16 out of 54 LGMD patients had children up to the time of assessment (table 1). However, when considering only interviewed married patients and taking years of marriage into account (children per patient per married year), no differences in the mean number of children could be seen in the three groups (table 1). Nevertheless, their reproductive peak occurred at different times. Patients affected with FSHMD reproduced significantly more before onset of the disease, whereas those with BMD reproduced significantly more after GC. However, although LGMD patients had $71 \%$ of their children born in the period between onset and GC, this reached no statistical significance (table 1 ).

Table 2 Factors associated with patients' reproduction and family planning

\begin{tabular}{|c|c|c|c|c|}
\hline Interviewed patients: & Yes $(\%)$ & No $(\%)$ & $N$ & $p$ \\
\hline High RR (FSHMD) and good retention of GC? & \multicolumn{4}{|c|}{ Had children after GC? } \\
\hline Yes & 28 & 72 & 7 & \multirow[t]{2}{*}{ NS } \\
\hline No & 27 & 73 & 11 & \\
\hline Already has children? & \multicolumn{4}{|c|}{ Wants (more) children? } \\
\hline Yes & 27 & 73 & 22 & \multirow[t]{2}{*}{$<0.05$} \\
\hline No & 56 & 44 & 39 & \\
\hline \multicolumn{5}{|l|}{ Has emotional/sexual dysfunction? } \\
\hline Yes & 36 & 64 & 45 & \multirow[t]{2}{*}{$<0.05$} \\
\hline No & 75 & 25 & 16 & \\
\hline \multicolumn{5}{|l|}{ Has high RR (FSHMD)? } \\
\hline Yes & 33 & 67 & 18 & \multirow[t]{2}{*}{ NS } \\
\hline No & 51 & 49 & 43 & \\
\hline \multicolumn{5}{|l|}{ Severe case? } \\
\hline Yes & 47 & 53 & 17 & \multirow[t]{2}{*}{ NS } \\
\hline No & 45 & 55 & 44 & \\
\hline \multicolumn{5}{|l|}{ Severe grade of physical disability $(V>6)$ ? } \\
\hline Yes & 25 & 75 & 12 & \multirow[t]{2}{*}{ NS } \\
\hline \multirow{2}{*}{\multicolumn{5}{|c|}{ Low socioeconomic level? }} \\
\hline & & & & \\
\hline Yes & 44 & 66 & 43 & \multirow[t]{2}{*}{ NS } \\
\hline No & 50 & 50 & 18 & \\
\hline \multicolumn{5}{|l|}{ Good comprehension of GC information? } \\
\hline Yes & 50 & 50 & 24 & \multirow[t]{2}{*}{ NS } \\
\hline No & 43 & 57 & 37 & \\
\hline Does not want to marry? & \multicolumn{4}{|c|}{ Emotional/sexual dysfunction? } \\
\hline Yes & 100 & 0 & 11 & \multirow[t]{2}{*}{$<0.05$} \\
\hline No & 60 & 40 & 25 & \\
\hline \multicolumn{5}{|l|}{ Severe case? } \\
\hline Yes & 88 & 12 & 17 & \multirow[t]{2}{*}{ NS } \\
\hline No & 68 & 32 & 44 & \\
\hline \multicolumn{5}{|l|}{ Severe grade of physical disability $(V>6)$ ? } \\
\hline Yes & 83 & 17 & 12 & \multirow[t]{2}{*}{ NS } \\
\hline No & 71 & 29 & 49 & \\
\hline Low socioeconomic level? & Good G & nation rete & & \\
\hline Yes & 33 & 67 & 43 & NS \\
\hline No & 56 & 44 & 18 & \\
\hline Shows emotional/sexual dysfunction? & & & & \\
\hline Yes & 40 & 60 & 45 & NS \\
\hline No & 38 & 62 & 16 & \\
\hline Severe grade of physical disability $(V>6)$ ? & & & & \\
\hline Yes & 25 & 75 & 12 & NS \\
\hline No & 43 & 57 & 49 & \\
\hline Severe case? & & & & \\
\hline Yes & 35 & 65 & 17 & NS \\
\hline No & 40 & 60 & 44 & \\
\hline Is affected with BMD? & & & & \\
\hline Yes & 39 & 61 & 21 & NS \\
\hline No & 40 & 60 & 40 & \\
\hline
\end{tabular}

Data refer only to cases with complete information. 
Comprehension and retention of information received during GC was reasonably good and the mean scores did not differ much between the three groups (table 1). Married BMD patients showed the best (1.67) and single patients with BMD the worst (1.06) observed retention of GC issues. Married LGMD patients also showed a low retention (1.17). Furthermore, there was no significant association of the retention of GC information with any of the factors analysed, socioeconomic level, prospective reproductive plans, emotional/sexual dysfunction, severe physical disability, nor with the type of disease (table 2).

Regarding prospective family planning (table 1) only a few of the married patients stated they wanted to have more children: $1 / 6$ of $\mathrm{BMD}$, $2 / 14$ of FSHMD, and 0/6 LGMD patients. However, it is interesting that 7/16 single BMD patients reported no wish to get married, in contrast to 4/16 LGMD and 0/4 FSHMD single patients. Twelve of 16 single men with LGMD, two of four FSHMD, and seven of 16 BMD declared they wanted to have their own biological children rather than adopt.

Table 2 shows no significant difference between the proportion of FSHMD patients (in comparison to LGMD and BMD) refraining from reproduction after GC, despite their high $R R$, even if considering only patients with good retention of GC information. Additionally, we did not find a significantly lower proportion of FSHMD patients with reproductive plans after GC. Instead, fewer patients with a desire to reproduce were observed among males who already had children (mean of 1.87 children per patient) and among those who presented emotional/sexual dysfunction in relating to the opposite sex, but not among those with severe grades of physical disability at time of assessment (table 2). All single patients who reported they did not ever wish to get married presented emotional/sexual dysfunction, which in turn was not found to be significantly associated with the severity of the disease. In addition, the disease's onset did not deter 40 out of 49 married and still childless patients from procreation (data not shown).

\section{Discussion}

Before discussing the results of the present study, it is important to observe that all patients analysed are males, and therefore pregnancy is not a burden to be considered in reproductive decisions as it would be if we had also included affected women in the cohort. We heard from many of our female patients with LGMD and FSHMD, for example, that they felt pregnancy had worsened their weakness and therefore they did not wish to have any further children, regardless of genetic risks. However, reproductive decisions of a couple may differ according to the gender of the affected person and should be the subject of a separate profound psychosocial investigation. Therefore, since in the present analysis, the aim was to disentangle the factors related to the affected person's reproductive decisions and future plans according to clinical severity and magnitude of $R R$, it was important to compare subjects of the same gender.

OBSERVATIONS COMMON TO THE THREE GROUPS Reproductive outcome

The present study shows that the total age specific reproductive outcome is associated with the severity of disease and age at onset. Reproductive outcome after GC has been shown not to be correlated with magnitude of $R R$; instead we found a significant association with the patient's past reproductive history, confirming some of the previous reports. ${ }^{18202132}$

\section{Comprehension and retention of recurrence risks} On the whole, comprehension and retention of information, particularly $R R$, received by our patients during GC was reasonably good and did not differ much between the three groups. Nevertheless, in accordance with previous studies, ${ }^{2133}$ the period of time after GC seems to influence retention, because single patients from all groups who had been counselled years before our married patients showed a poorer $\mathrm{RR}$ retention score. Another possible explanation is that unmarried patients who are trying to cope with their progressive weakness may be more concerned about what will happen to them than about future potential genetic risks for their offspring. However, to allow statistical analysis, patients' statements on RR comprehension and retention have been reduced to a three point scale, which might have made differences among the groups less evident. Therefore, these results should be considered with caution.

\section{Prospective family planning}

According to the present results, prospective family planning is significantly associated with past reproductive history, also reported by other authors, ${ }^{18202132}$ as well as with emotional/ sexual dysfunction. All interviewed subjects who did not want to marry and thus did not want any children showed emotional/sexual problems, but there was no significant correlation with the severity of their clinical course. Also surprising is the fact that severe grades of physical disability (almost to loss of ambulation) among married and still childless patients is not significantly associated with reduced reproductive plans for the future. However, as the sample of severe cases and of patients showing $\mathrm{V}>6$ at assessment is relatively small, these statements should also be regarded with caution. It will be interesting to observe if the interviewed patients really fulfil their stated reproductive plans in the future.

\section{SPECIFIC OBSERVATIONS}

\section{FSHMD}

In the present study high recurrence risks (RR), characteristic of FSHMD, were not found to be associated with a significantly lower reproductive outcome after GC nor with a reduced desire for (further) children, even if considering only patients with good comprehension/retention of GC information. Although the sample of patients with FSHMD and good GC information retention is rela- 
tively small, these surprising apparent contradictions have also been observed by other authors ${ }^{142023243234}$ and support our previous results on FSHMD in both sexes, ${ }^{35}$ where only 11 out of 29 patients stated that GC had influenced their family planning and only $2 / 29$ would have avoided transmitting the deleterious gene to their children had they known about their diagnosis earlier. The contradiction of patients not diminishing reproduction despite their high $R R$ is attributed to the complexity of the conscious and unconscious aspects of the decision process involved in family raising. ${ }^{22} 2536$

On the other hand, our results are in sharp contrast to some other reports where (1) $44 \%$ of American counsellees with different diseases reported GC had influenced their reproductive plans $^{19}$; (2) $67 \%$ of persons at risk for Huntington's disease who had reproductive plans decided to refrain from having children or to have PND after they knew about their carrier status ${ }^{37}$; and (3) French patients who reported the shock experienced when they heard that their FSHMD was hereditary. ${ }^{38}$ The high public awareness of muscular dystrophies (especially DMD) in France since the first Telethon in 1987 leads to fears of extreme severity in recently diagnosed patients and to alleviation of mental pain in those diagnosed long before. ${ }^{38}$ As public awareness of muscular dystrophies is only beginning to be an issue in Brazil, their severity and heredity are perceived directly by the patients or based upon observation of affected relatives or acquaintances and their families. Thus, the notion of heredity among Brazilian counsellees is not as threatening as it seems to be for the French (mainly because of the lack of information) resulting in an age specific reproductive outcome very similar to that of the general population, as observed in the present study.

It is important to note that FSHMD patients are usually less severely affected than patients with the other types of PMD studied here and cope better with their disease, particularly in respect to working and socioeconomic issues. ${ }^{31}$ There are many reasons which lead Brazilian FSHMD patients to procreate as often as the general population, despite their high RR. For example, these patients stated they wanted to have children like everybody else for reasons such as: "Since I can live fairly well with this disease, why shouldn't an affected child of mine?", "I would feel better having somebody else in the family with my condition", "Maybe a child of mine, if affected, could seek treatment more easily", or "If I have a rather difficult time with this disease I want to have many children, affected or not, to live the life I cannot live anymore", or even "To help me when I will be completely dependent".

FSHMD patients may also take into consideration affected relatives from earlier generations to decide whether or not to have children. For example, an FSHMD male patient and his wife were referred for PND, but the couple was not sure they wanted to interrupt the pregnancy if the deleterious gene had been inherited. DNA testing showed a female fetus carrying the FSHMD gene. When the couple was informed about this result they decided to continue the pregnancy, mainly because the fetus was female, with the argument that the husband's mother (who was also affected) had a very mild condition. However, the possibility of clinical anticipation in FSHMD which has been observed by us $^{39}$ and others ${ }^{40}{ }^{41}$ was not taken into consideration in their decision.

\section{$B M D$}

In accordance with our previous paper on reproductive fitness, ${ }^{42}$ we also observed a lower reproductive outcome in $\mathrm{BMD}$ compared to LGMD in the present study, for the following reasons. Severe BMD cases have a significantly reduced tendency to get married and thus to have children, as expected. However, additionally, emotional factors are also deterring young BMD patients from marriage and therefore from procreation, although many of them are not severe cases. This leads to a lower mean number of children per BMD patient, considering married and single patients together. According to some of the patients followed up weekly in group dynamic sessions, ${ }^{31}$ emotional problems are more pronounced in the phases preceding total loss of ambulation and therefore it is expected that patients who are wheelchair bound later will consequently have procreated more. In this respect, it would be interesting to analyse if patients while losing ambulation really avoid contact with the opposite sex, postponing or even refraining from future marriage and family raising. Interestingly, for FSHMD, Dellaporte ${ }^{38}$ reported that patients feel relieved after a certain period of mourning, necessary for them fully to accept their disease, and change their life accordingly in a positive manner. Therefore, it can be speculated that, contrary to what one might think, some patients with a severe course (and early loss of ambulation) can actually recover from the mourning process in time to overcome emotional/sexual problems and still marry and reproduce. In fact, we have observed BMD patients who married just before loss of ambulation and now are happily taking care of their babies while their wives go out to work.

Once married, there seems to be no physical barrier for BMD patients to have children, at least in the first years of marriage. Even if they present Vignos $>6$ (almost non-ambulant) they do not significantly refrain from their reproductive plans. On the contrary, it could be speculated that the wish for (more) children is an attempt to compensate for the total loss of ambulation. Nevertheless, one expects that progression of physical weakness and the lowered life expectancy reduces total reproductive fitness even among married BMD patients.

Surprisingly, BMD patients reproduced more after GC than any other group. Possible explanations for this fact are that they were reassured by the genetic counsellor that all their children would be clinically normal or they had fewer children before GC than the other groups because they were younger and therefore reproduced relatively more after GC. 
Married BMD patients showed the best and single patients the worst $R R$ retention, which could be the effect of time on memory, since single patients have been counselled, on average, five years before married patients. Moreover, there are indications that some of the factors influencing $R R$ retention are unconscious, such as, for example, its perception (rather than its objective magnitude), which has been shown to increase the search for genetic tests in the case of breast cancer. ${ }^{43}$ Additionally, the emotional context linked to a disease acts upon the retention of its $R R$, since women who suffered more because of their child's Down syndrome had a greater probability of retaining the $R R^{44}$ If "suffering more" is associated with more severe diseases, one would expect severely affected patients to show a better retention of their $R R$, but we found that married $B M D$ patients retained them best, while single BMD patients retained them worst of all. Since our single patients are more severely affected than our married patients, "suffering more" does not enhance retention of RR among the patients studied. This observation suggests that the patient's age as well as their marital status and therefore their interest in procreation may have a greater influence on retention than "suffering".

\section{LGMD}

Although we detected time as an influencing factor for $R R$ retention in BMD, married LGMD patients showed poor retention, although they had been counselled only one year before assessment, suggesting other factors to be important. One possibility is that since in the first assessment they are informed of their low $R R$, this issue is poorly retained because they do not need to worry about it any more.

Since LGMD confers no risk in the absence of consanguineous marriage, these patients reproduce according to their degree of physical ability, their past reproductive history, and their emotional/sexual dysfunction. In one case a LGMD male patient married his first degree "at risk" cousin and the couple decided to delay reproduction for years until genetic testing was possible. Recently, DNA tests showed that the wife is heterozygous for the LGMD gene and the couple remain childless, although the possibility of prenatal diagnosis was offered to them, suggesting emotional difficulties in dealing with abortion of a fetus who will be affected with the same disease as the father (see below).

\section{SOME CONSIDERATIONS ON GENETIC}

COUNSELING IN DEVELOPING COUNTRIES

It is important to discuss why high RRs do not significantly reduce reproduction after GC among Brazilian patients. It was observed that risk interpretation is very complex and almost impossible to separate from other factors, even in countries where the mean socioeconomic level is much higher than in Brazil. ${ }^{22} 45$

How can recurrence risk be expressed in a qualitative manner, since this is this way it is internalised by the patients ? $^{45}$ According to the majority of genetic counsellors, GC should be non-directive, , $^{3246}$ but it is questionable whether this can ever be possible to achieve. ${ }^{36}{ }^{47}$ According to a recent study, ${ }^{48}$ half of the counsellees interviewed felt they had been steered by the counsellor and no association was found between counsellor reported and counsellee reported and rated directiveness or between these measures and counsellees' anxiety and concern, satisfaction with information, or the meeting of counsellees' expectations. This means that genetic counselling cannot be considered uniformly non-directive. Additionally, some patients' satisfaction with GC is better when counselling really means giving advice and some authors draw the conclusion that more neutral counselling is related to a higher client risk perception, owing, perhaps, to the misconception that bad news is being concealed. ${ }^{49-51}$

Finally, although it is agreed that GC should be non-directive, in particular because of the misuse of eugenics in the past, this is difficult to achieve in practice. Questions such as "What would you do in my place?" are often heard during GC. It is important to point out that in underdeveloped countries there are three additional difficulties: (1) many "at risk" families lack basic education with all its consequences; (2) there is no social support from the government for handicapped persons and this represents a very heavy burden for the families involved; and (3) although the possibility of therapeutic abortion is discussed during GC and supported in private practice, the interruption of pregnancy for genetic as well as social reasons is still prohibited by law in Brazil. (At present, legalisation for abortion is being courageously fought for by some of our health professionals.) It is also important to state that any suggestion to adult patients with PMD about non-procreation or interruption of pregnancy in the case of an affected fetus can be interpreted as "your life is not worth living" or even "you should have been aborted", as may be the case in the above discussed LGMD patient married to his first cousin, not (yet?) willing to undergo PND. Therefore, we suggest that genetic counsellors should make every possible effort to make sure that all information on $R R$ as well as the subtle psychosocial implications, especially in countries such as ours, are fully understood, discussed, and taken into consideration by other health professionals as well, in order to allow the counsellees to make the best decision for themselves as far as possible on their own.

We are especially grateful to the patients and their families. We also acknowledge the following persons for diagnosis and genetic counselling: Dr Maria Rita Passos-Bueno, Dr Mariz Vainzof, Dr Rita de Cassia M Pavanello, Dr Ivo Pavanello, Antonia Cerqueira, Marta Canovas, and Simone Campiotto. We also thank Constancia Urbani and the staff of ABDIM (Associação Brasileira de Distrofia Muscular) who made the interviews possible and evaluated the patients' physical condition. We also thank the anonymous referee for valuable comments. This study was supported by FAPESP, CNPq, PRONEX, and ABDIM.

1 Emery AEH. The muscular dystrophies. In: Emery AEH, Rimoin D, eds. Principles and practice of medical genetics. Vo 1. Edinburgh: Churchill Livingstone, 1993:392-413.

2 Kunkel LM, Hejtmancik JF, Caskey CT, et al. Analysis of deletions in DNA from patients with Becker and Duchenne muscular dystrophy. Nature 1986;322:73-7. 
3 Nicholson GA, Davidson K, Falkous G, et al. Dystrophin in skeletal muscle. I. Western blot using monoclonal antibody. f Neurol Sci 1989;94:125-36.

4 Nicholson GA, Johnson MA, Gardner-Medwin D, Bhattacharya S, Harris JB. Heterogeneity of dystrophin expression in patients with Duchenne muscular dystrophy. Acta Neuropathol 1990;80:239-50.

5 Beckmann JS, Richard I, Hillaire D, et al. A gene for limb-girdle muscular dystrophy maps to chromosome 15 by linkage. CR Acad Sci III 1991; 312:141-8.

6 Othmane B, Hamida BM, Pericak-Vance M, et al. Linkage of Tunisian autosomal recessive Duchenne-like muscular of Tunisian autosomal recessive Duchenne-like muscular dystrophy to the pericentrome

7 Bashir R, Strachan T, Keers S, et al. A gene for autosomal recessive limb-girdle muscular dystrophy maps to chromosome 2p. Hum Mol Genet 1994;3:455-7.

8 Roberds ST, Leurdq F, Allamand V, et al. Missense mutations in the adhalin gene linked to autosomal recessive muscular dystrophy. Cell 1994;78:625-33.

9 Bönnemann CG, Modi R, Nogushi S, et al. $\beta$-sarcoglycan (A3b) mutations cause autosomal recessive muscular dystrophy with loss of the sarcoglycan complex. Nat Genet 1995;11:266-70.

10 Lim LE, Duclos F, Broux O, et al. $\beta$-sarcoglycan: characterization and role in limb-girdle muscular dystrophy linked to 4q12. Nat Genet 1995;11:257-64.

11 Passos-Bueno MR, Moreira ES, Vainzof M, Zatz $M$. Linkage analysis in autosomal recessive limb-girdle muscular dystrophy (AR LGMD) maps a sixth form to 5q33-34 lar dystrophy (AR LGMD) maps a sixth form to 5q33-34 (LGMD2F) and indicates that there is at least one more
subtype of AR LGMD. Hum Mol Genet 1996;5:815-20.

12 Wijmenga C, Sandkuijl LA, Moerer P, et al. Genetic linkage Wijmenga C, Sandkuijl LA, Moerer P, et al. Genetic linkage
map of facioscapulohumeral muscular dystrophy and five polymorphic loci on chromosome 4q35-qter. Am f Hum Genet 1992;51:411-15.

13 Padberg G. Facioscapulohumeral disease. $\mathrm{PhD}$ thesis, University of Leiden, The Netherlands, 1982.

14 Evers-Kiebooms G, Van Der Berghe H. Impact of genetic counselling: a review of follow-up studies. Clin Genet 1979; 15:465-74.

15 Black RB. The effects of diagnostic uncertainty and available options on perceptions of risk. Psychological available options on pelling VI. A critical review of the literature dealing with education and reproduction. $A m \mathcal{F}$ Med Genet 1989;34:340-53.

16 Abramovsky I, Godmillow L, Hirschhorn K, Smith H. Analysis of a follow up study of genetic counselling. Clin Analysis of a follow

17 Zatz M. Effects of genetic counselling on Duchenne muscular dystrophy families in Brazil. Am $7 \mathrm{Med}$ Genet 1983;15:483-90.

18 Sissine FL, Rosser L, Steele MW, Marchese S, Garner KL, Berman N. Statistical analysis of genetic counselling impacts: a critical review of the literature dealing with education and reproduction. Am $\mathcal{F}$ Hum Genet 1981;34:34053.

19 Wertz DC, Sorenson JR. Client reactions to genetic counseling: self-reports of influence. Clin Genet 1986;30 494-502.

20 Sorenson JR, Scoutch NA, Swazey JP, Wertz DC, Heeren TC. Reproductive plans of genetic counselling clients no eligible for prenatal diagnosis. Am $\mathcal{f}$ Med Genet 1987;28: 549-55.

21 Swerts A. Impact of genetic counselling and prenata diagnosis of Down syndrome and neural tube defects. Psydiagnosis of Down syndrome and neural tube defects. Psychosocial aspects of genetic counselling. VI. A critica review of the literature dealing with educatio

22 Kessler S. Psychosocial aspects of genetic counselling. VI. A critical review of the literature dealing with education and reproduction. Am $\mathcal{F}$ Hum Genet 1989;34:340-53

23 Frets PG, Duivenvoorden HJ, Verhage F, Ketzer E Niermeijer MF. Model identifying the reproductive decision after genetic counselling. Am 7 Med Genet 1990;35: 503-9.

24 Frets PG, Duivenvorden HJ, Verhage F, et al. Factors influencing the reproductive decision after genetic counselling. Am F Med Genet 1990;35:496-502.

25 Frets PG, Verhage F, Martinus F. Characteristics of the postcounselling reproductive decision-making process: an posplorative study. Am $\Im$ Med Genet 1991;40:298-30.

26 IBGE (Instituto Brasileiro de Geografia e Estatística). Censo Demográfico do Município de São Paulo, 1980.

27 Archibald KC, Vignos PJ. A study of contractures in Archibald KC, Vignos PJ. A study of contractures in
muscular dystrophies. Arch Phys Med Rehab 1959;40:1507.
28 Brooke $M H$ Fenichel G, Grigos RC, et al. Clinical investigation in Duchenne dystrophy. 2. Determination of the "power" of therapeutic trials based on the natural history. Muscle Nerve 1983;6:91-103.

29 Bushby KMD, Gardner-Medwin D. The clinical, genetic and dystrophin characteristics of Becker muscular dystrophies. 1 . Natural history. $\mathcal{F}$ Neurol 1993;240:98-104.

30 WHO. Disability Assessment Schedule. Geneva: World Health Organization, 1988.

31 Eggers S, Zatz $M$. Social adjustment in adult males affected with progressive muscular dystrophies. Am $\mathcal{F}$ Med Genet (Neuropsych Genet) (in press).

32 Wertz DC, Fletcher JC. Ethics and medical genetics in the United States: a national survey. Am $\mathcal{Y}$ Med Genet 1984;29: 815-27.

33 Sorenson JR, Swazey JP, Scoutch NA. Reproductive pasts, reproductive futures. Genetic counselling and effectiveness. New York: Alan R Liss, 1981

34 Rona RJ, Beech R, Mandalia S, et al. The influence of genetic counselling in the area of DNA testing on knowledge, reproductive intentions and psychological wellbeing. Clin Genet 1994;46:198-204.

35 Eggers S, Passos-Bueno MR, Zatz M. Facioscapulohumeral muscular dystrophy: aspects of genetic counselling, acceptance of preclinical diagnosis, and fitness. $\mathcal{f}$ Med Gener 1993;30:589-92.

36 Kessler S. Psychological aspects of genetic counseling. VII Thoughts on directiveness. F Genet Couns 1992;1:9-18.

37 Decruyenaere M, Evers-Kiebooms G, Boogaerts A, et al. Prediction of psychological functioning one year after predictive test for Huntington's disease and impact of the test dictive test for Huntington's disease and impact of the test 33:737-43.

38 Delaporte C. Ways of announcing a late-onset, heritable, disabling disease and their psychological consequences. Genet Couns 1996;7:289-96.

39 Zatz M, Marie SK, Passos-Bueno MR, et al. High proportion of new mutations and possible anticipation in Brazilian facioscapulohumeral muscular dystrophy famiBrazilian facioscapulohumeral muscular

40 Lunt PW, Jardine PE, Koch MC, et al. Correlation between fragment size at $\mathrm{D} 4 \mathrm{fl} 104 \mathrm{~S} 1$ and age at onset or at wheelchair use, with a possible generational effect, accounts for much phenotypic variation in $4 \mathrm{q} 35$ facioscapulohumeral muscular dystrophy (FSHD). Hum Mol Genet 1995;4:951-8.

41 Tawil R, Forrester J, Griggs RC, et al. The FSH-DY groups (1996) evidence for anticipation and association of deletion size with severity in facioscapulohumeral muscular dystrophy. Ann Neurol 1996;39:744-8.

42 Eggers $\mathrm{S}$, Lauriano V, Melo $\mathrm{M}$, et al. Why is the reproductive performance lower in Becker (BMD) as compared to limb girdle (LGMD) muscular dystrophy male patients? $\mathrm{Am}$ Med Genet (Neuropsych Genet) 1995;60:27-32.

43 Struewing IP, Lerman C, Kase RG, Giambarresi TR, Tucker MA. Anticipated uptake and impact of genetic testing in hereditary breast and ovarian cancer families. Cancer Epidemiol Biomarkers Prev 1995;4:169-73.

44 Ekwo EE, Seals BF, Kim JO, Williamson RA, Hanson JW. Factors influencing maternal estimates of genetic risk. $A m$ F Med Genet 1985,15:465-74.

45 Lippman-Hand A, Fraser FC. Genetic counselling: parent's responses to uncertainty. Psychosocial aspects of genetic counseling. VI. A critical review of the literature dealing with education and reproduction. Am $\mathcal{f}$ Hum Genet 1989;34:340-53.

46 Wertz DC, Fletcher JC. Attitudes of genetic counselors: multinational survey. Am f Hum Genet 1988;42:592-600.

47 Clarke $A$. Is non-directive genetic counselling possible? Lancet 1991;338:998-1001.

48 Michie S, Bron F, Bobrow M, Marteau TM. Nondirectiveness in genetic counseling: an empirical study. Am f Hum Genet 1997;60:40-7.

49 Shiloh S, Saxe L. Perception of risk in genetic counseling Psychol Health 1989;3:45-61.

50 Shiloh S, Avdor O, Goodman RM. Satisfaction with genetic counselling. Dimensions and measurement. $\mathrm{Am} \mathcal{F} \mathrm{Med}$ Genet 1990;37:522-9.

51 Shiloh S. Decision-making in the context of genetic risk. In Marteau T, Richards M, eds. The troubled helix. Social and psychological implications of the new human genetics. Psychological implications of the new huma 